Canadian University Music Review

Revue de musique des universités canadiennes

\title{
Léonard A. Rosmarin. When Literature Becomes Opera: Study of a Transformational Process. Amsterdam et Atlanta : Rodopi, 1999. 160 p. ISBN 90-420-0694-3
}

\section{Louis Bilodeau}

Volume 20, numéro 1, 1999

URI : https://id.erudit.org/iderudit/1015657ar

DOI : https://doi.org/10.7202/1015657ar

Aller au sommaire du numéro

Éditeur(s)

Canadian University Music Society / Société de musique des universités canadiennes

ISSN

0710-0353 (imprimé)

2291-2436 (numérique)

Découvrir la revue

Citer ce compte rendu

Bilodeau, L. (1999). Compte rendu de [Léonard A. Rosmarin. When Literature Becomes Opera: Study of a Transformational Process. Amsterdam et Atlanta : Rodopi, 1999. 160 p. ISBN 90-420-0694-3]. Canadian University Music Review / Revue de musique des universités canadiennes, 20(1), 133-134. https://doi.org/10.7202/1015657ar

All Rights Reserved (C Canadian University Music Society / Société de musique des universités canadiennes, 2000
Ce document est protégé par la loi sur le droit d'auteur. L’utilisation des services d’Érudit (y compris la reproduction) est assujettie à sa politique d'utilisation que vous pouvez consulter en ligne.

https://apropos.erudit.org/fr/usagers/politique-dutilisation/ 
it is an overview of performances of and performers in Fidelio. It offers a chronicle of the stagings of this opera from its premiere in 1805 , threatened by Napoleon's occupation of Vienna, through interpretations by Alfred Roller (conducted by Gustav Mahler) and Wieland Wagner, to that of Jonathan Miller, first performed in 1982 and conducted by Roger Norrington. Robinson shows that productions of Fidelio have gone full circle, with the most recent attempting a return to the world in which it premiered, that of the French Revolution.

Paul Robinson's Fidelio is a worthy addition to the series of Cambridge Opera Handbooks. It follows the concept and design of its predecessors, and is easily their equal in terms of scholarly level and readability, while still permitting the author licence to impose something of his personal stamp on the interpretative process. It provides the mid-level student with an introduction to one of the most eminent achievements of the operatic world, while pointing the way to further research for those who wish to pursue the topic further.

Alison Stonehouse

Léonard A. Rosmarin. When Literature Becomes Opera : Study of a Transformational Process. Amsterdam et Atlanta : Rodopi, 1999. 160 p. ISBN 90-420-0694-3.

Dans cet ouvrage, Léonard Rosmarin cherche à montrer quels sont les principes qui président au phénomène de transformation d'un texte littéraire en livret d'opéra. Afin de mener à bien son objectif, l'auteur propose l'étude de huit livrets d'opéra parmi les plus célèbres du répertoire et qui s'inspirent tous d'auteurs français des $\mathrm{XIX}^{\mathrm{e}}$ et $\mathrm{XX}^{\mathrm{e}}$ siècles : Rigoletto, La traviata, Carmen, Thaïs, La bohème, Tosca, Pelléas et Mélisande et Dialogues des Carmélites. L'étude se compose de deux parties de longueur à peu près égale. Dans le premier chapitre, "Reinforcing the Centre of Gravity », Rosmarin dégage les principales différences entre les livrets et les œuvres les ayant inspirés. Il décrit comment les librettistes ont nécessairement dû élaguer les œuvres littéraires pour mettre l'accent sur un aspect, ce centre de gravité autour duquel gravitent tous les éléments retenus ou modifiés par rapport aux textes originaux. Ainsi, Rosmarin montre que Rigoletto s'articule tout entier autour de la malédiction de Monterone ou que Dialogues des Carmélites développe principalement le thème du transfert de la grâce. Rosmarin s'étant limité à l'étude de chefs-d'œuvre de l'histoire de l'opéra, on aurait tort de lui reprocher son enthousiasme en regard du travail d'adaptation de Piave, Gallet ou Meilhac et Halévy. Il a également tout à fait raison d'insister sur le pouvoir expressif de la musique, qui supplée amplement à ce que le livret doit passer sous silence, notamment dans le cas de Thaïs. Je ne puis cependant souscrire à tous ses jugements d'ordre littéraire, en particulier en ce qui concerne Victor Hugo, qu'il écorche au passage en affirmant que sa production théâtrale est mélodramatique dans le sens péjoratif du terme (p. 15). Ce genre de remarque ignore que le drame romantique est très voisin du mélodrame et que, de plus, presque toute l'œuvre de Verdi ressortit précisément à cette esthétique du mélodrame très en vogue 
au XIX ${ }^{\mathrm{e}}$ siècle, comme l'a bien démontré Gilles de Van dans le chapitre 8 de son Verdi, un théâtre en musique (Fayard, 1992).

Dans la seconde partie, "The Creation of Exemplary Figures ", Rosmarin s'attache à préciser en quoi les personnages des opéras qu'il a choisis constituent des archétypes; comment, par exemple, Violetta est la courtisane qui se sanctifie par son sacrifice ou comment Carmen incarne l'idée de liberté. Cette deuxième section reprend l'analyse de chacune des œuvres où la première les avait laissée et adopte la même approche, c'est-à-dire une étude qui suit pas à pas le résumé de l'intrigue avec de nombreuses citations du livret.

Ce livre saura plaire aux lecteurs découvrant l'art lyrique et possédant une connaissance plus ou moins grande du corpus abordé par Rosmarin. En ce sens, il constitue un bon ouvrage de vulgarisation et réussira sans doute à sensibiliser bien des amateurs d'opéra à la question extrêmement complexe du phénomène d'adaptation. Le lecteur plus critique ne sera toutefois pas comblé, car l' analyse des différentes œuvres demeure en définitive sommaire et bien peu originale. L'auteur s'appuie très souvent sur ses illustres devanciers comme Joseph Kerman, William Ashbrook ou Peter Conrad et s'excuse parfois de ne pas partager leurs idées. Outre les quelques auteurs cités précédemment, Rosmarin se réfère à de nombreuses reprises aux divers articles de L'Avant-Scène Opéra. L'auteur passe malheureusement sous silence trop de sources essentielles pour qu'on ne lui en tienne pas rigueur. Je m'étonne ainsi du fait que la très bonne synthèse de Patrick Smith sur l'histoire du livret (The Tenth Muse) ne figure pas dans la bibliographie. L'important article de Maurice Descotes sur les adaptations à l'opéra des pièces de Hugo (Revue d'histoire du théâtre $34, \mathrm{n}^{\circ} 2$ [1982] : 103-56) aurait également mérité au moins une mention, de même que deux publications consacrées au livret comme genre littéraire : le numéro $4 / 5$ de L'Alphée (Opéra et Littérature, 1981) et Le livret malgré lui (Publimuses, 1991). Ce dernier recueil comprend notamment une étude très fouillée par Vincent Vivès d'un thème abordé par Rosmarin : " Du livret à l'aventure prosodique : Dialogues des Carmélites ou le transfert de la grâce ». Il aurait enfin été intéressant de laisser davantage la parole aux librettistes et en particulier à Louis Gallet, dont plusieurs articles montrent bien la petite révolution engendrée par son livret de Thaïs (1894), écrit dans une forme apparentée à la prose. Cela dit, peut-être mes attentes étaient-elles trop grandes par rapport à cet ouvrage, qui demeure une bonne introduction à huit opéras fascinants.

Louis Bilodeau 